Check for updates

Cite this: RSC Adv., 2018, 8, 30163

\title{
Direct conversion of C6 sugars to methyl glycerate and glycolate in methanol $\dagger$
}

\begin{abstract}
Lei Feng, Gang Li, Yueer Yan, Wenrong Hou, Yahong Zhang (D) and Yi Tang (DD*
The present work deals with the one-pot conversion of C6 sugars to methyl glycerate and glycolate via a cascade of retro-aldol condensation and oxidation processes catalyzed by using $\mathrm{MoO}_{3}$ as the Lewis acid catalyst and $\mathrm{Au} / \mathrm{TiO}_{2}$ as the oxidation catalyst in methanol. Methyl glycerate (MGLY) is the product of $\mathrm{C} 6$ ketose (fructose), while methyl glycolate (MG) is produced from C6 aldose (mannose, glucose). It is found that a good one-pot match between two reactive processes is the key to the production of MGLY and MG with high yield (27.6\% MGLY and 39.2\% MG). A separated retro-aldol condensation and oxidation process greatly decreases their yields, and even no MGLY can be obtained in this separated process. We attribute this to high instability of glyceraldehyde/glycolaldehyde and their different reaction pathways which mainly depend on whether acetalization of retro-aldol products (glyceraldehyde and glycolaldehyde) occurs with methanol or not. This result opens a new prospect on the accumulation of C3 products other than lactate from biomass-derived carbohydrates.
\end{abstract}

Received 1st July 2018

Accepted 17th August 2018

DOI: $10.1039 / \mathrm{c} 8 \mathrm{ra05612a}$

rsc.li/rsc-advances

methanol by using nanoparticle Au catalyst under mild reac-

\section{Introduction}

Much attention has been devoted to research on chemicals from renewable biomass in recent years. ${ }^{1-4}$ As the largest fraction of biomass, carbohydrates are acknowledged as an abundant and inexpensive source of carbon for the production of fuels and value-added chemicals. ${ }^{5-8}$ Nowadays, although a variety of strategies have been developed to convert carbohydrates into diverse platform chemicals containing C2 to C6 skeletons, ${ }^{9-15}$ a mild and highly efficient catalytic route is still desired, particularly for chemicals with high thermal instability. Methyl glycerate (MGLY) and methyl glycolate (MG) are industrially important chemicals, which can be regarded as solvents, extractants or as food additives. More importantly, they are also used as platform molecules in the synthesis of macromolecule polymer material. ${ }^{\mathbf{1 6 - 2 0}}$ So far, many strategies, e.g., the coupling of formaldehyde and methyl formate, and the hydrogenation of dimethyl oxalate, have been developed to prepare MG from the different conventional substrates, and the corresponding catalysts containing heteropolyacids and homogenous organic metal or heterogeneous metal catalysts have been explored. ${ }^{21-25}$ Additionally, MG was also obtained from the oxidation of biomass-derived ethylene glycol in

Department of Chemistry, Shanghai Key Laboratory of Molecular Catalysis and Innovative Materials, Laboratory of Advanced Materials, Collaborative Innovation Centre of Chemistry for Energy Materials (iChEM), Fudan University, Shanghai 200433, China. E-mail: zhangyh@fudan.edu.cn; yitang@fudan.edu.cn; Fax: +86021-65643288; Tel: +86-021-65643288

$\dagger$ Electronic supplementary information (ESI) available. See DOI: 10.1039/c8ra05612a tion conditions. ${ }^{26,27}$ Using the similar catalytic system, Heeres et al. studied the oxidative esterification of glycerol to MGLY. ${ }^{28}$ However, the direct production of MG and MGLY from sustainable biomass sugars is still desired. Recently, Zhang and co-workers reported the preparation of MG from cellulosic biomass by using tungsten-containing compounds as catalysts in methanol. ${ }^{29}$ Han et al. employed phosphomolybdic acid to prepare glycolic acid from cellulose in water. ${ }^{30}$ To obtain glycolic acid and its methyl ester, high temperature is an essential condition in their works. Nevertheless, this is not conducive to the production of MGLY because of the high instability of glyceraldehyde (GLA) produced in the retro-aldol process of hexose. ${ }^{31,32}$ Therefore, in the previous reports on C3 product of biomass sugar, only dehydration product of GLA, i.e., lactate, can be obtained in such catalytic system. ${ }^{33,34}$ There have been few reports on generating MGLY from C6 sugars or cellulose. Herein, we developed a one-pot catalytic system for the direct production of MGLY and MG from C6 ketose and aldose via a cascade of retro-aldol condensation and oxidation processes catalyzed by $\mathrm{MoO}_{3}$ as Lewis acid catalyst and nanoparticle $\mathrm{Au}$ supported on $\mathrm{TiO}_{2}\left(\mathrm{Au} / \mathrm{TiO}_{2}\right)$ as oxidative catalyst, respectively. Moreover, a good one-pot match between two reaction processes is the key to obtain MG and MGLY with high yield. And it is found that a separated twostep process, i.e., separated retro-aldol condensation and oxidation processes, can decline their yields, and even no MGLY can be obtained by the two-step process. This can be attributed to the high instability of GLA and its different oxidative route from GA. 


\section{Experimental section}

\section{Materials}

D-(+)-Mannose (MAN, 99\%), D-(+)-glucose (GLU, 99.5\%), D(-)-fructose (FRU, 99\%), glycolaldehyde dimer (GA, 95\%) and D(-)-glyceraldehyde (GLA, 90\%) were purchased from SigmaAldrich. Methyl glycolate (MG, 98\%), 1,3-dihydroxyacetone (DHA, 99\%), pyruvaldehyde (PYR, 40\%), methyl lactate (ML, 98\%), methanol (99.9\%) were purchased from Macklin. Methyl glycerate (MGLY, 95\%) was purchased from Molbase. Molybdenum(vi) oxide $\left(\mathrm{MoO}_{3}\right)$ and potassium carbonate were purchased from Sinopharm Chemical Reagent Company. Gold nanoparticle supported on titanium oxides $\left(\mathrm{Au} / \mathrm{TiO}_{2}\right.$ : gold $1 \%$ on titanium dioxide) was purchased from Aladdin. Deionized water was produced by a laboratory water purification system.

\section{Catalyst characterization}

A Bruker D2 diffractometer, taken from $5^{\circ}$ to $80^{\circ}$ with $\mathrm{Cu} \mathrm{K} \alpha$ radiation $(\lambda=0.154 \mathrm{~nm})$, was employed for obtaining the X-ray diffraction (XRD) patterns of $\mathrm{MoO}_{3}$ and $\mathrm{Au} / \mathrm{TiO}_{2}$ catalysts. The morphology of the $\mathrm{Au} / \mathrm{TiO}_{2}$ was determined by transmission electron microscopy (TEM, Tecnai G2 F20 S-Twin, USA FEI Corp.). The scanning electron microscopy (SEM, Nova NanoSem 450, USA FEI Corp.) was employed to observe morphology of $\mathrm{MoO}_{3}$ catalyst.

$\mathrm{NH}_{3}$-temperature programmed desorption (TPD) was used to determine the acid property of $\mathrm{MoO}_{3}$. Typically, $1.4 \mathrm{~g}$ of the sample was loaded in a U-shape quartz reactor, pretreated at $600{ }^{\circ} \mathrm{C}$ for $1 \mathrm{~h}$ and then cooled to $100{ }^{\circ} \mathrm{C}$ under He flow. The pretreated sample was saturated with $5 \% \mathrm{NH}_{3} / \mathrm{He}$ for $1 \mathrm{~h}$ at $100{ }^{\circ} \mathrm{C}$, with subsequent flushing at $100{ }^{\circ} \mathrm{C}$ for $1 \mathrm{~h}$ to remove the physisorbed ammonia. TPD analysis was carried out from 100 to $480{ }^{\circ} \mathrm{C}$ at a heating rate of $10 \mathrm{~K} \mathrm{~min}^{-1}$. Quantitative analysis of the desorbed ammonia was based on Thermal Conductivity Detector (TCD).

\section{Catalytic reaction procedure}

All the catalytic reactions were carried out in a $30 \mathrm{~mL}$ thickwalled glass reactor. Briefly, $50 \mathrm{mg}$ of C6 sugar was dissolved in $5 \mathrm{~g}$ of methanol. And then, 12.5-50 mg of $\mathrm{MoO}_{3}$ and 40$100 \mathrm{mg}$ of $\mathrm{Au} / \mathrm{TiO}_{2}$ were added, respectively. Subsequently, the glass reactor containing reaction mixture was put into microwave instrument and pressurized with oxygen to $1 \mathrm{MPa}$ and was heated to desired temperature under stirring with a magnetic stirring $(600 \mathrm{rpm})$. For the conversion of FUR, a little amount of $\mathrm{K}_{2} \mathrm{CO}_{3}(3 \mathrm{mg}$ ) was added to form a weak alkaline environment for the purpose of easy oxidation process. ${ }^{35-37}$ After reacting for a certain time, the reactor was cooled to room temperature by compressed air. The mixture of liquid and solid was filtered to separate the solid catalysts from liquid fraction. The quantitative analysis of methanol-soluble products in the liquid fraction was conducted by high-performance liquid chromatography (Shimadzu, HPLC) and gas chromatography (Shimadzu, GC). And the solid fractions by filtration after the reaction were loaded in the reactor again to investigate the reusability of the catalysts. Additionally, the transformations of GA/GLA into MG/
MGLY as well as the transformations of C6 sugars into GA/GLA were performed in the above same procedure, but either $100 \mathrm{mg}$ of $\mathrm{Au} / \mathrm{TiO}_{2}$ or $50 \mathrm{mg}$ of $\mathrm{MoO}_{3}$ were added as single catalyst. Moreover, no $\mathrm{O}_{2}$ was needed during the catalytic process of $\mathrm{C} 6$ sugars into GA/GLA.

\section{Product analysis}

Conversion of the substrate and yield of the product, except MGLY, were analysed on a Shimadzu HPLC (RI detector) equipped with a Shodex SC1011 (30 cm length) sugar column maintained at $80{ }^{\circ} \mathrm{C}$ using deionized water as the mobile phase with a flow rate of $1.0 \mathrm{~mL} \mathrm{~min}^{-1}$. The quantification analyses of samples were based on calibration curves obtained by injecting standard solutions of known concentrations (Fig. S1 $\dagger$ ). MGLY was analysed on GC (Shimadzu, FID detector) equipped with DC-FFAP capillary column $(30 \mathrm{~m} \times 0.25 \mathrm{~mm} \times 0.25 \mu \mathrm{m})$. The injector and detector temperatures were set at $250{ }^{\circ} \mathrm{C}$ and $250{ }^{\circ} \mathrm{C}$. Nitrogen was used as the carrier gas with a flow rate of $1.0 \mathrm{~mL} \mathrm{~min}^{-1}$. The split ratio was $1: 100$. GC-MS (Thermo Finnign Voyager, with a HP-Wax column of dimension $30 \mathrm{~m} \times$ $0.25 \mathrm{~mm} \times 0.25 \mu \mathrm{m}$ and electron impact ionization) was used to confirm the products. Both the products of C6 ketose and aldose were further identified by the mass spectra. And ${ }^{1} \mathrm{H}$ nuclear magnetic resonance (NMR) spectrum was performed to identify the reaction pathways of C6 ketose to MGLY and C6 aldose to MG. Conversion of substrate and carbon yield of product were calculated as follow.

For the conversion of C6 sugars into GA/GLA and MG/MGLY:

Conv.Retro-aldol $=\left[1-\frac{\text { moles of hexose in the product }}{\text { initial moles of hexose }}\right] \times 100 \%$

$Y_{\mathrm{GA} / \mathrm{MG}}=\left[\frac{1}{3} \times \frac{\text { moles of } \mathrm{GA} / \mathrm{MG} \text { in the product }}{\text { initial moles of hexose }}\right] \times 100 \%$

$$
\begin{aligned}
Y_{\mathrm{GLA} / \mathrm{MGLY}}= & {\left[\frac{1}{2} \times \frac{\text { moles of GLA } / \text { MGLY in the product }}{\text { initial moles of hexose }}\right] } \\
& \times 100 \%
\end{aligned}
$$

$$
\begin{aligned}
Y_{\mathrm{DHA} / \mathrm{PYR} / \mathrm{ML}}= & {\left[\frac{1}{2} \times \frac{\text { moles of } \mathrm{DHA} / \mathrm{PYR} / \mathrm{ML} \text { in the product }}{\text { initial moles of hexose }}\right] } \\
& \times 100 \%
\end{aligned}
$$

For the conversion of GA into MG:

$$
\begin{gathered}
\text { Conv. } \cdot \mathrm{GA} \\
=\left[1-\frac{\text { moles of GA in the product }}{\text { initial mole of GA }}\right] \times 100 \% \\
Y_{\mathrm{MG}}=\left[\frac{\text { moles of MG in the product }}{\text { initial moles of GA }}\right] \times 100 \%
\end{gathered}
$$


$Y_{\text {hexose }}=\left[3 \times \frac{\text { moles of hexose in the product }}{\text { initial moles of GA }}\right] \times 100 \%$

$$
\begin{aligned}
Y_{\mathrm{PYR} / \mathrm{DHA}}= & {\left[\frac{3}{2} \times \frac{\text { moles of } \mathrm{PYR} / \mathrm{DHA} \text { in the product }}{\text { initial moles of } \mathrm{GA}}\right] } \\
& \times 100 \%
\end{aligned}
$$

For the conversion of GLA into MGLY:

$$
\text { Conv.GLA }=\left[1-\frac{\text { moles of GLA in the product }}{\text { initial moles of GLA }}\right] \times 100 \%
$$

$Y_{\mathrm{MGLY} / \mathrm{PYR} / \mathrm{DHA} / \mathrm{ML}}=$

$\left[\frac{\text { moles of MGLY } / \text { PYR/DHA/ML in the product }}{\text { initial moles of GLA }}\right] \times 100 \%$

$$
\begin{gathered}
Y_{\mathrm{MG}}=\left[\frac{2}{3} \times \frac{\text { moles of MG in the product }}{\text { initial moles of GLA }}\right] \times 100 \% \\
Y_{\text {hexose }}=\left[2 \times \frac{\text { moles of hexose in the product }}{\text { initial moles of GLA }}\right] \times 100 \%
\end{gathered}
$$

\section{Results and discussion}

\section{One-pot conversion of various C6 sugars}

To enable the productions of MGLY and MG from C6 sugars, a retro-aldol process and an oxidative esterification process are necessary (Scheme 1). As shown in Scheme 1, MGLY can be produced from C6 ketose (FRU) while MG is the product of C6 aldose (MAN, GLU) via a retro-aldol process and an oxidative esterification process. $\mathrm{MoO}_{3}$, as a suitable solid catalyst with good capacity to catalyze 1,2-intramolecular carbon shift, ensures that the retro-aldol process of C6 sugars can be achieved smoothly at moderate temperature. ${ }^{38-40}$ Such moderate retro-aldol reaction condition is very critical to its combination

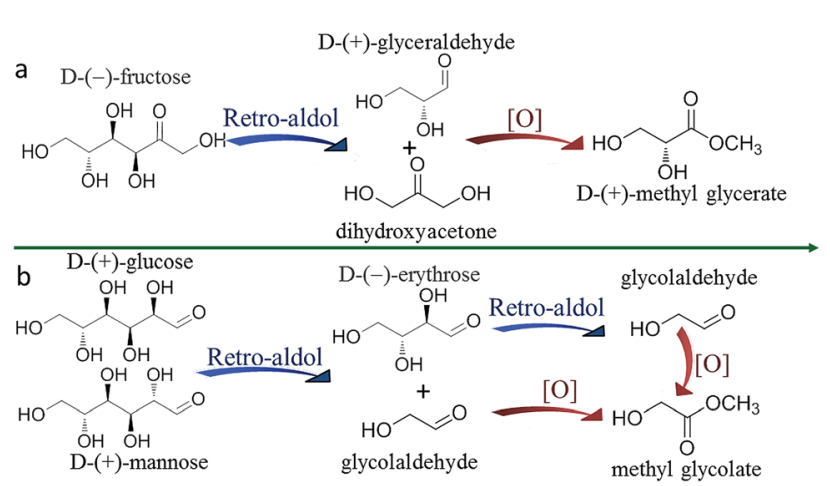

Scheme 1 Direct conversion of C6 sugars to MGLY and MG via a retro-aldol process and an oxidative esterification process. with the oxidative esterification process and the avoidance of the further side reactions such as dehydration, polymerization and over-oxidation of the retro-aldol products. Furthermore, for the oxidation catalyst, several conventional commercial noble metal catalysts are pre-screened by using GA as substrate. As shown in Table $\mathrm{S} 1, \uparrow \mathrm{Au} / \mathrm{TiO}_{2}$ displays a compelling advantage on the oxidation of GA compared to other catalysts $(\mathrm{Pt} / \mathrm{C}, \mathrm{Pd} / \mathrm{C}$ and $\mathrm{Ru} / \mathrm{C}$ ). Therefore, herein, $\mathrm{MoO}_{3}$ and $\mathrm{Au} / \mathrm{TiO}_{2}$ catalysts are employed to jointly perform the conversion of C6 sugars toward MGLY and MG although a number of Lewis acid catalysts used in the retro-aldol process have been reported. ${ }^{\mathbf{4 1 - 4 4}}$

XRD, SEM and $\mathrm{NH}_{3}$-TPD analyses were used to characterize the crystalline structure, size and acid activity of the used commercial $\mathrm{MoO}_{3}$ (Fig. 1a-c). The diffraction peaks in Fig. 1a at $2 \theta=12.8^{\circ}, 23.3^{\circ}, 25.7^{\circ}, 27.3^{\circ}, 38.9^{\circ}$ can be indexed to the reflection of (020), (110), (040), (021) and (060), which displays a typical layered $\alpha-\mathrm{MoO}_{3}$ crystalline structure. The SEM image in Fig. 1b further confirms its laminate structure with a micro scale. Moreover, $\mathrm{NH}_{3}$-TPD result of $\mathrm{MoO}_{3}$ indicates that there is a maximum ammonia desorption at $\sim 150{ }^{\circ} \mathrm{C}$ in the range $100-$ $480{ }^{\circ} \mathrm{C}$ of desorption profile (Fig. 1c), implying its Lewis acidity. The acid amount of $\mathrm{MoO}_{3}$ is $9.2 \times 10^{-2} \mathrm{~cm}^{3} \mathrm{~g}^{-1} \mathrm{STP}$, which has been gotten by the Quantitative analysis of the desorbed ammonia based on Thermal Conductivity Detector (TCD). Furthermore, the XRD pattern of $\mathrm{Au} / \mathrm{TiO}_{2}$ in Fig. 1a exhibits that only crystalline phase of $\mathrm{TiO}_{2}$ can be observed and no diffraction of $\mathrm{Au}\left(38.2^{\circ}, 44.4^{\circ}, 64.6^{\circ}, 77.5^{\circ}\right)$ can be found, which can be attributed to the small size and low amount of $\mathrm{Au}$ on the supported $\mathrm{TiO}_{2}$. And the size of Au nanoparticle is measured from TEM images and its size distribution is evaluated according to the images of hundreds of randomly selected particles, that is, its average size is calculated at $2 \mathrm{~nm}$ with statistic method (Fig. 1d).

The conversion of various $\mathrm{C} 6$ sugars in methanol was carried out in the presence of the above $\mathrm{MoO}_{3}$ and $\mathrm{Au} / \mathrm{TiO}_{2}$, and the results were listed in Table 1 . Obviously, the data in Table 1
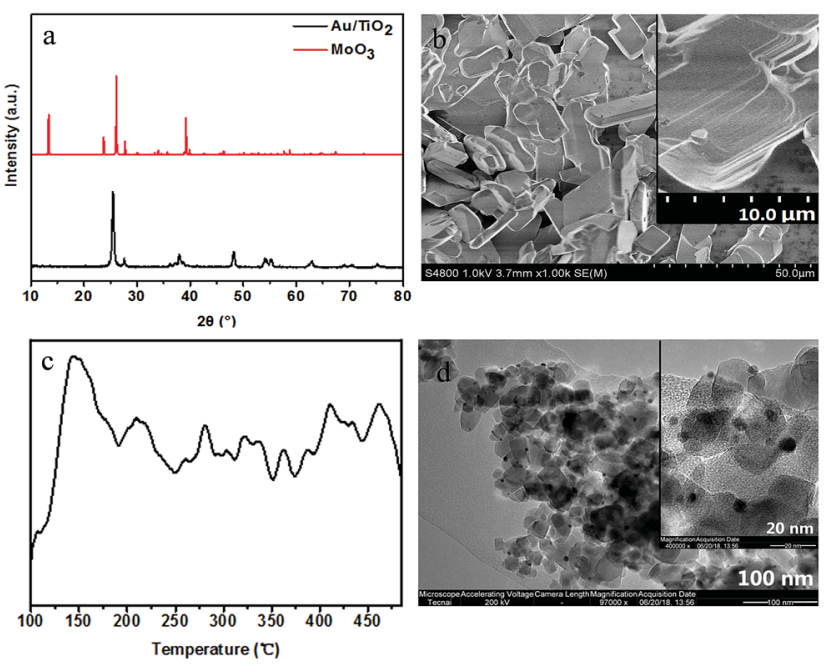

Fig. 1 (a) XRD patterns of $\alpha-\mathrm{MoO}_{3}$ and $\mathrm{Au} / \mathrm{TiO}_{2}$; (b) SEM image of $\alpha$ $\mathrm{MoO}_{3}$; (c) $\mathrm{NH}_{3}$-TPD profile of the $\alpha-\mathrm{MoO}_{3}$ and (d) TEM of image of $\mathrm{Au} /$ $\mathrm{TiO}_{2}$. 
Table 1 Direct conversion of C6 sugars to MGLY and MG in methanol

\begin{tabular}{|c|c|c|c|c|c|c|}
\hline Substrate & $T(\mathrm{~K})$ & $t(\mathrm{~h})$ & Conv-Retro-aldol (mol\%) & Selec. (C mol\%) & $Y(\mathrm{C}$ mol\% $)$ & Carbon balance (mol\%) \\
\hline \multirow[t]{5}{*}{$\mathrm{FRU}^{a}$} & & & & MGLY & & \\
\hline & 353 & 5 & 73.9 & 30.2 & 22.3 & 74.2 \\
\hline & & 3 & 72.4 & 28.9 & 20.9 & 73.9 \\
\hline & & 5 & 85.3 & 32.4 & 27.6 & 70.4 \\
\hline & & 6 & 87.2 & 31.4 & 27.4 & 68.6 \\
\hline & & 2 & 41.9 & 51.0 & 21.4 & 91.5 \\
\hline & & 3 & 53.8 & 50.5 & 27.2 & 89.4 \\
\hline & & 4 & 55.2 & 56.5 & 31.2 & 88.7 \\
\hline & & 5 & 55.8 & 57.9 & 32.3 & 87.5 \\
\hline \multirow[t]{2}{*}{$\operatorname{MAN}^{c}$} & 393 & 1 & 72.5 & 33.4 & 24.2 & 78.0 \\
\hline & & 2 & 77.8 & 42.0 & 32.7 & 74.8 \\
\hline & & 2 & 50.8 & 37.0 & 18.8 & 77.9 \\
\hline & & 3 & 52.5 & 37.3 & 19.6 & 77.7 \\
\hline & & 4 & 54.2 & 38.7 & 21.0 & 74.3 \\
\hline & & 5 & 56.9 & 36.3 & 20.7 & 71.2 \\
\hline
\end{tabular}

${ }^{a}$ Reaction conditions: $50 \mathrm{mg}$ of FRU, $5 \mathrm{~g}$ of methanol, $50 \mathrm{mg}$ of $\mathrm{MoO}_{3}, 100 \mathrm{mg}$ of $\mathrm{Au} / \mathrm{TiO}_{2}$ and $3 \mathrm{mg}$ of $\mathrm{K}_{2} \mathrm{CO}_{3}, 1 \mathrm{MPa}_{2}{ }^{b}$ Reaction conditions: $50 \mathrm{mg}$ of MAN, $5 \mathrm{~g}$ of methanol, $50 \mathrm{mg}$ of $\mathrm{MoO}_{3}, 100 \mathrm{mg}$ of Au/TiO${ }_{2}, 1 \mathrm{MPa} \mathrm{O}{ }_{2}{ }^{c}$ Reaction conditions: $50 \mathrm{mg}$ of MAN, $5 \mathrm{~g}$ of methanol, $37.5 \mathrm{mg}$ of $\mathrm{MoO}_{3}, 80 \mathrm{mg}$ of $\mathrm{Au} / \mathrm{TiO}_{2}, 1 \mathrm{MPa} \mathrm{O}_{2} .{ }^{d}$ Reaction conditions: $50 \mathrm{mg}$ of GLU, $5 \mathrm{~g}$ of methanol, $50 \mathrm{mg}$ of $\mathrm{MoO}_{3}, 100 \mathrm{mg}$ of Au/TiO, $1 \mathrm{MPa} \mathrm{O}$. Yields $(Y)$ of all products are calculated by carbon atom yields from the original hexoses. Selectivity (Selec.) of MGLY is calculated by $Y_{\text {MGLY }}$ Conv .Retro-aldol $\times 100 \%$, and the corresponding carbon balance is calculated by $\left[1-\right.$ Conv $\left._{\text {Retro-aldol }}+Y_{\text {MGLY }}+Y_{\text {others }}\right] \times 100 \%$, others: GLA, DHA, PYR, ML. Selectivity (Selec.) of MG is calculated by $Y_{\mathrm{MG}} /$ Conv. . Retro-aldol $\times 100 \%$, and the corresponding carbon balance is calculated by $[1-$ Conv $\cdot$ Retro-aldol $\left.+Y_{\text {MG }}+Y_{\text {others }}\right] \times 100 \%$, others: GA, DHA.

show that MGLY and MG can be smoothly obtained from C6 ketose and aldose, respectively. To be specific, the selectivity and yield of MGLY increase with the increasing reaction time, the highest yield of MGLY can reach $27.6 \%$ within $5 \mathrm{~h}$ at $363 \mathrm{~K}$ (Table 1, Fig. S2 $\dagger$ ). Meanwhile, the dehydration products of GLA, such as pyruvaldehyde (PYR) and methyl lactate (ML), increase with reaction time also (Table S2 $\dagger$ ). Moreover, low reaction temperature is more favourable to isomerization of hexoses rather than its retro-aldol splitting. However, as shown in Fig. S3 $\uparrow$ and Table 1, the main product is MG instead of MGLY when FRU is replaced by C6 aldose (MAN or GLU). The two aldoses display the similar product distributions in the presence of $\mathrm{MoO}_{3}$ and $\mathrm{Au} / \mathrm{TiO}_{2}$ (Table S3 $\dagger$ ), and the highest selectivity and yield of MG are obtained within $4 \mathrm{~h}$ at $393 \mathrm{~K}$. However, likely due to higher isomerization and epimerization tendency of GLU than MAN, GLU gives a lower yield of MG than MAN (Table 1). Besides, it can also be observed in Table 1 that high reaction temperature and long reaction time can result in a decreasing carbon balance. Because of the instability of substrates/intermediates, the increasing reaction temperature and time can induce the formation of undetectable humin/tar, and so decrease detectable carbon of the reaction system. Furthermore, the formations of MGLY and MG were further confirmed by GC-MS (Fig. S4 and S5†) and MS (Fig. S6†) results of their reaction solutions, respectively. It is worth noting that glyceric acid (Fig. S4a and S6a†े) and glycolic acid (Fig. S5c and $\mathrm{S} 6 \mathrm{~b} \dagger)$ are well observed in their reaction solutions except for
MGLY and MG, respectively. Moreover, during the conversion of MAN, the acetal product of GA (1,1,2-trimethoxyethane, 2,2dimethoxyethanol) and glycosidic MG are detected also (Fig. S5a, d, e and S6b $\dagger$ ), indicating the acetalation/ glycosidation reactions of GA/MG with methanol.

\section{Two-step conversion of C6 sugars}

In the experiment, we found that only trace of MGLY was obtained when the conversion of FRU toward MGLY was divided into two steps to carry out, i.e., $\mathrm{MoO}_{3}$-driven retro-aldol process first and then the oxidative esterification process catalyzed by $\mathrm{Au} / \mathrm{TiO}_{2}$ later. This indicates that this one-pot integrated process is very favour of the formation of MGLY. To gain further insight into the conversion of FRU to MGLY (Scheme 1), the retro-aldol process of FRU catalyzed by $\mathrm{MoO}_{3}$ and oxidative esterification process of the corresponding triose (GLA) catalyzed by $\mathrm{Au} / \mathrm{TiO}_{2}$ were investigated and optimized, respectively. According to the results shown in Table S4, $\uparrow$ only about $5.0 \%$ of GLA can be achieved within the reaction of $3 \mathrm{~h}$ at $373 \mathrm{~K}$ when only $\mathrm{MoO}_{3}$ is added. Moreover, a certain amount of pyruvaldehyde (PYR) and methyl lactate (ML) can be obtained. This means that GLA is difficult to be stably accumulated in the single retro-aldol process of FRU, and it can further not only dehydrate into PYR and ML but also split into formaldehyde and GA. Therefore, the yield of GLA is very low in the conversion of FRU to GLA (Table S4 $\uparrow$ ). This high instability of GLA also results in a low yield of MGLY even if GLA is directly used as 
substrate in its oxidative esterification process (Table $\mathrm{S} 5 \dagger$ ). Therefore, a real-time transformation of GLA, i.e., a one-pot process containing retro-aldol condensation and oxidative esterification processes together, pays to the formation of MGLY from FRU. Moreover, it is worth mentioning that the MGLY obtained from this one-pot process is a chiral compound because chiral center in $\alpha$-carbon of GLA has not been influenced during the retro-aldol splitting of D-FRU toward GLA, which will be significant for its further transformation and practical application. Generally, this chiral MGLY can only be obtained by biological fermentation process. ${ }^{45}$

Besides, the retro-aldol process of MAN and the oxidative esterification process of GA were also investigated and the reaction conditions were optimized. Unlike the case of GLA, GA can be stably obtained in methanol (Table S6 $\dagger$ ) and it can be also high selectively converted into MG (Table S7†). In more details, as shown in Table $S 6, \uparrow$ a short reaction time $(1 \mathrm{~h})$ and a high temperature (393 K) benefit the accumulation of GA, that is, a $45.4 \%$ of GA can be obtained from MAN in the presence of $\mathrm{MoO}_{3}$ within $1 \mathrm{~h}$ at $393 \mathrm{~K}$. However, for the oxidative esterification of GA, the highest yield of MG can be obtained at $373 \mathrm{~K}$ (Table S7 $\dagger$ ). Therefore, we try to achieve the conversion of MAN toward MG via a two-step process under their optimum reaction conditions, that is, MAN is treated in the presence of $\mathrm{MoO}_{3}$ for $1 \mathrm{~h}$ at $393 \mathrm{~K}$ (Table 2 , step 1 ), and then reaction mixture is further catalyzed by $\mathrm{Au} / \mathrm{TiO}_{2}$ under the $1 \mathrm{MPa}$ of $\mathrm{O}_{2}$ at $373 \mathrm{~K}$ for desired time after solid $\mathrm{MoO}_{3}$ is removed. A $30.4 \%$ of $\mathrm{MG}$ is ultimately obtained (Table 2, step 2), which is still lower than that $(39.2 \%)$ achieved in the one-pot system. This result further demonstrates that the one-pot integrated process is conductive to the formation of methyl ester. In such one-pot catalytic system, the produced GLA/GA during the retro-aldol of C6 sugars can be timely converted by the oxidative esterification, which not only shifts the retro-aldol equilibrium toward right but also avoids the side reaction. Therefore, MG and MGLY are produced more efficiently from C6 sugars by the combination of $\mathrm{MoO}_{3}$ with $\mathrm{Au} / \mathrm{TiO}_{2}$.

In addition, it is worth mentioning that $\mathrm{MoO}_{3}$ can also give an oxidation activity by the reduction of $\mathrm{Mo}(\mathrm{VI})$ to $\mathrm{Mo}(\mathrm{Iv}){ }^{38}$ which means that oxidative products could be formed in the presence of only $\mathrm{MoO}_{3}$. However, in our experiments, when only $\mathrm{MoO}_{3}$ is used as catalyst, only retro-aldol process of FRU/MAN can be observed and no MGLY or MG can be detected.

Table 2 Two-step conversion of MAN toward MG in methanol ${ }^{a}$

\begin{tabular}{lllllll}
\hline Step & $T(\mathrm{~K})$ & $t(\mathrm{~h})$ & $\begin{array}{l}\text { Conv.Retro-aldol } \\
(\mathrm{mol} \%)\end{array}$ & $\begin{array}{l}\frac{Y_{\mathrm{GA}}}{(\mathrm{C} \mathrm{mol} \%)} \\
\frac{Y_{\mathrm{MG}}}{2}\end{array}$ & $\begin{array}{l}\text { Carbon } \\
\text { balance (mol\%) }\end{array}$ \\
\hline 1 & 393 & 1 & 71.1 & 45.6 & 0 & 74.5 \\
2 & 373 & 1 & 76.4 & 3.5 & 29.5 & 59.3 \\
& & 2 & 78.8 & 3.2 & 30.4 & 56.8
\end{tabular}

${ }^{a}$ Reaction conditions: $50 \mathrm{mg}$ of MAN, $5 \mathrm{~g}$ of methanol, $50 \mathrm{mg}$ of $\mathrm{MoO}_{3}$ (step 1); $5 \mathrm{~mL}$ reaction solution of step 1 without $\mathrm{MoO}_{3}, 100 \mathrm{mg}$ of $\mathrm{Au} /$ $\mathrm{TiO}_{2}, 1 \mathrm{MPa} \mathrm{O}$ (step 2). Yields $(Y)$ of products are calculated by carbon atom yield from the original hexose. Carbon balance is calculated by [1 - Conv.Retro-aldol $\left.+Y_{\mathrm{GA}}+Y_{\mathrm{MG}}+Y_{\mathrm{DHA}}\right] \times 100 \%$.
However, similar to that of literature, ${ }^{38}$ a long reaction time (more than $5 \mathrm{~h}$ ) could partly lead to the colour change of $\mathrm{MoO}_{3}$ from white to dark blue although no MGLY or MG can be observed, indicating the existence of other complex oxidized byproducts. Moreover, when $\mathrm{MoO}_{3}$ is used in the presence of $\mathrm{O}_{2}$, the colour change of $\mathrm{MoO}_{3}$ becomes negligible because of the oxidizing environment. Furthermore, if $\mathrm{MoO}_{3}$ is used in the presence of $\mathrm{O}_{2}$, as shown in Table S8, $\uparrow$ only trace amount of MG can be observed with the reaction of $3 \mathrm{~h}$, which can be attributed to the oxidation of $\mathrm{O}_{2}$ with a low activity. Even if the reaction time is prolonged to $9 \mathrm{~h}$, only $10.8 \%$ of MG is achieved (Table S8 $\dagger$ ). Therefore, we can confirm that the $\mathrm{MoO}_{3}$ and $\mathrm{Au} /$ $\mathrm{TiO}_{2}$ in the presence of $\mathrm{O}_{2}$ are responsible for the retro-aldol activity and oxidative activity during the conversion of hexoses toward MGLY and MG, respectively.

\section{Optimization of reaction conditions and recycling of catalysts}

In further maximizing the yields of MG and MGLY, the amount and the ratio of two catalysts were optimized also. As shown in Fig. 2a (left) and Table $\mathrm{S} 9, \dagger$ high or low mass ratio of $\mathrm{MoO}_{3}$ to $\mathrm{Au} / \mathrm{TiO}_{2}$ results in a low selectivity and yield of MGLY, and the highest yield of MGLY is obtained within $5 \mathrm{~h}$ when their mass ratio is set to 1 : 2 (50 $\mathrm{mg} \mathrm{MoO}_{3}$ and $\left.100 \mathrm{mg} \mathrm{Au} / \mathrm{TiO}_{2}\right)$. Similar to that of MGLY formation, the highest yield of MG can be obtained when the mass ration of $\mathrm{MoO}_{3}$ to $\mathrm{Au} / \mathrm{TiO}_{2}$ is about $1: 2$ (Table $\mathrm{S} 10 \dagger$ ). These results indicate that an appropriate match between the amounts of two catalysts is the key to obtain the product with high yield. Under these optimal conditions, the influences of hexose concentration in the MGLY/MG yields were studied (Fig. 2, Table S11 and S12 $\dagger$ ). It is found that changes in the FRU concentration from 1.0 to $10.0 \mathrm{wt} \%$ do not significantly affect the yield of MGLY, and nearly $20 \%$ of MGLY was obtained even at a high FRU concentration of $10 \mathrm{wt} \%$ (Fig. 2a, right). However, as shown in Fig. 2b (left), although there is not obvious change in the yield of MG when the concentration of MAN is increased from 1.0 to $2.0 \mathrm{wt} \%$, MG yield decreased significantly with the increase of MAN concentration from 2.0 to $10.0 \mathrm{wt} \%$. In a word, a low hexose concentration is beneficial to their direct conversion toward MGLY/MG. Subsequently, we also tested the prospect of reusing solid $\mathrm{MoO}_{3}$ and $\mathrm{Au} / \mathrm{TiO}_{2}$ in the reaction of producing MG from MAN (Fig. 2b, right, Table
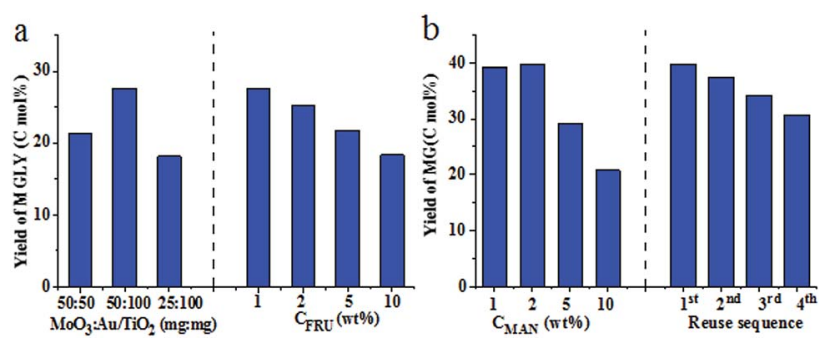

Fig. 2 (a) Carbon yield of MGLY for FRU conversion in methanol containing different mass ratios of $\mathrm{MoO}_{3}$ to $\mathrm{Au} / \mathrm{TiO}_{2}$ (left), and different FRU concentrations (right); (b) carbon yield of MG for MAN conversion in methanol with different MAN concentrations (left), and reuse of $\mathrm{MoO}_{3}$ and $\mathrm{Au} / \mathrm{TiO}_{2}$ catalysts. 
$\mathrm{S} 13 \dagger)$. After a reaction cycle was finished, the used $\mathrm{MoO}_{3}$ and $\mathrm{Au} / \mathrm{TiO}_{2}$ catalysts were filtered out directly from the reaction system and then were added into the next cycle experiment of the conversion of MAN to MG as catalysts. It is found that the MG yield is slightly dropped after four cycles, which could be caused by the part aggregation of $\mathrm{Au}$ nanoparticles loaded on the $\mathrm{TiO}_{2}$ from $2 \mathrm{~nm}$ to $5 \mathrm{~nm}$ during the recyclability test experiment (Fig. 1d vs. Fig. S7†). The slight activity decrease of $\mathrm{Au}$ nanoparticle can be also confirmed by the slight accumulation of GA in the fourth cycle in Table S13. $\uparrow$ Because the conversion of in situ produced GA from retro-aldol process of MAN to MG is converted into MG under the catalysis of $\mathrm{Au} / \mathrm{TiO}_{2}$, the activity decrease of $\mathrm{Au} / \mathrm{TiO}_{2}$ catalyst results in the accumulation of GA in the reaction system.

\section{Reaction pathway}

According to the above results, we can conclude that MG can be obtained through both one-pot and two-step processes, but MGLY can only be accumulated in the one-pot process. Moreover, it is found that the acetal product of GA (1,1,2-trimethoxyethane, 2,2-dimethoxyethanol) and glycosidic MG can be observed in the products during the conversion of MAN (Fig. S5 and $\mathrm{S} 6 \mathrm{~b} \dagger)$, however, no corresponding derivative species of GLA in the conversion of FUR can be detected. Based on these facts, we propose that the formations of MGLY and MG from hexoses experience different routes (Scheme 2), which could be responsible for their different reaction results in the above two reaction processes. In our proposed reaction routes, after C6 aldose and ketose is split into GA and GLA via retro-aldol process, respectively, GA can react with methanol at once and convert into dimethoxyethanol and 1,1,2-trimethoxyethane via acetalization process, and then the acetal products can be further oxidized into MG (Scheme 2). However, the produced GLA is inclined to directly convert into glyceric acid and MGLY in the presence of $\mathrm{Au} / \mathrm{TiO}_{2}$ and $\mathrm{O}_{2}$ (Scheme 2). Obviously, taking the instability of aldehyde group into account, its acetalization with methanol can make it stable within a short time. Therefore, the acetalization of GA in methanol assures its stability and accumulation during the retro-aldol process (Table S6†), and so MG can be obtained in the two-step process due to the good stability of GA acetal (Table 2). On the contrary, GLA tends to further dehydrate into PYR and ML or split into GA and formaldehyde because of its instability (Tables S4 and S5†). To confirm this, ${ }^{1} \mathrm{H}$-NMR analyses of GA and GLA in methanol before/after thermal treatment were studied. Moreover, to avoid

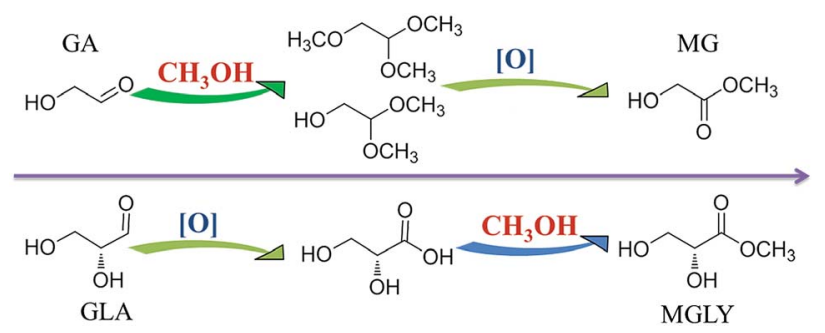

Scheme 2 The proposed different reaction pathways of GA to MG and GLA to MLGY. the other side reactions, no catalyst was added during the thermal treatment. As shown in Fig. 3a, a simple thermal treatment (393 $\mathrm{K}$ for $30 \mathrm{~min}$ ) results in significant change of ${ }^{1} \mathrm{H}$ chemical shifts of GA. For instance, the aldehyde $\mathrm{H}-1$ resonated at 9.61 ppm disappears whereas two new chemical shifts appear at 4.48 and $4.37 \mathrm{ppm}$, which can be assigned to those $\mathrm{H}$ of acetal and hemiacetal of aldehyde in GA (Fig. S8 $\dagger$ ). However, the ${ }^{1} \mathrm{H}$ chemical shifts of GLA before/after thermal treatment display few change, indicating that no other product of GLA is formed in methanol (Fig. 3b). Additionally, the stability effect of acetalation process on GA can be further confirmed by the conversion of GA in methanol. As shown in Table S14, $\dagger$ when GA is directly added into methanol in the absence of oxidation catalyst, it displays a very low conversion in HPLC analysis because of deacetalization of acetal product during the elution process even if the thermal treatment temperature is increased to $190{ }^{\circ} \mathrm{C}$. However, its GC result shows that the acetal product

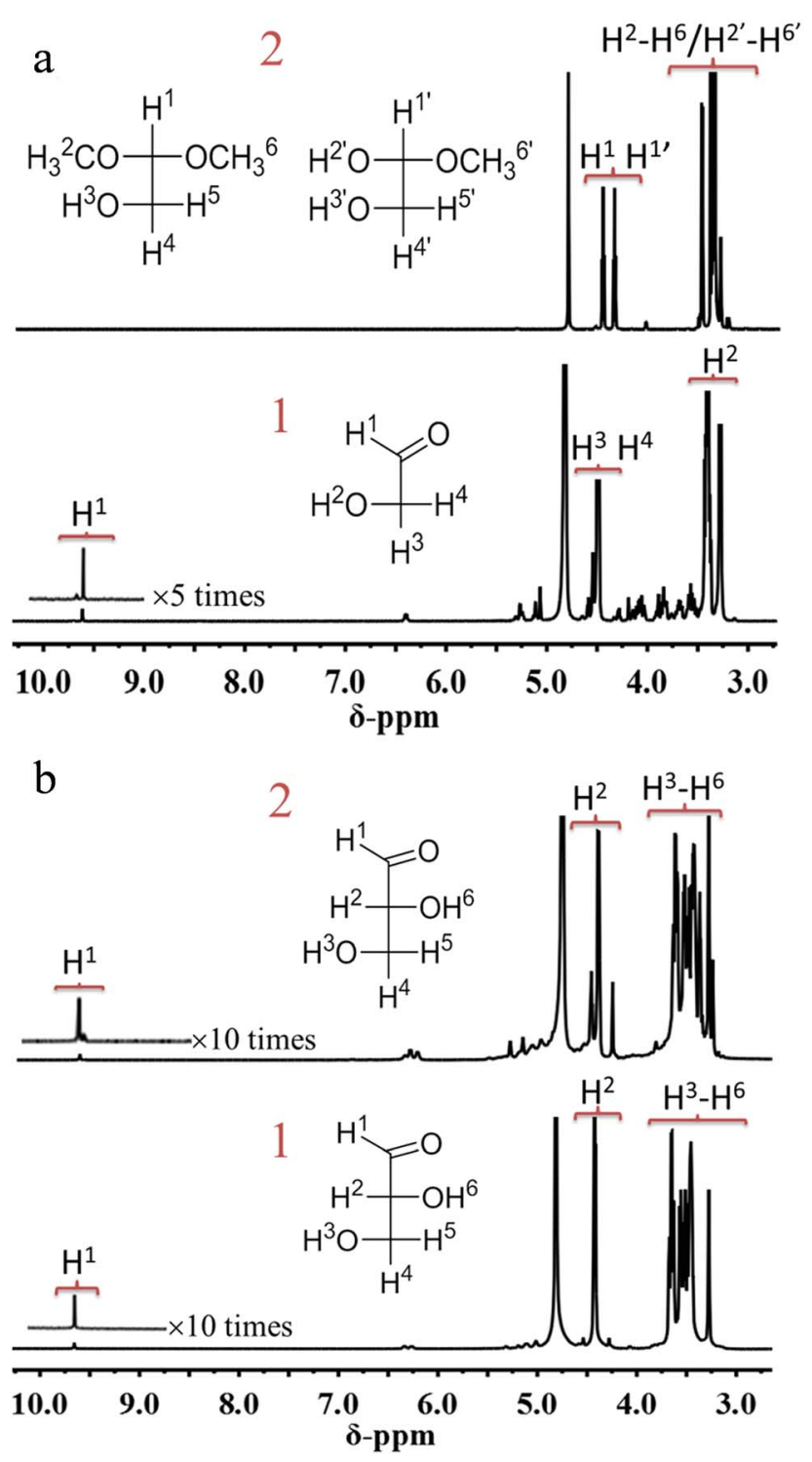

Fig. 3 (a) ${ }^{1} \mathrm{H}-\mathrm{NMR}$ spectra of GA in methanol before (1)/after (2) thermal treatment, (b) ${ }^{1} \mathrm{H}-\mathrm{NMR}$ spectra of GLA in methanol before (1)/ after (2) thermal treatment. 
is observed and its yield can be more than $90 \%$. This demonstrates not only the dominant acetalation process of GA in methanol but also its stabilization effect on GA. On the contrary, the difficult acetalation of GLA facilitates the formation of ML, and so leads to the poor accumulation of GLA. These results further support our proposed formation routes of MGLY and MG (Scheme 2). This finding of solvent effect also provides the possibility to stabilize the active products and so achieve a high product yield and even to change the product distribution.

\section{Conclusions}

We have proposed a one-pot strategy to prepare MGLY and MG from biomass-derived hexoses in the presence of $\mathrm{MoO}_{3}$ and $\mathrm{Au} /$ $\mathrm{TiO}_{2}$. It is found that a good match between two cascade reactions is the key to obtain MG and MGLY with high yield, and a separated two-step process, i.e., separated retro-aldol condensation and oxidation processes, can decline their yields because of the high instability of GLA and GA. We also proposed that the formations of MGLY and MG from hexoses experience different reaction routes, and whether acetalation of instable aldehyde group with methanol plays an important role on the yields of MGLY and MG. The results provide a new glimpse on the accumulation of the instable product via a solvent effect. Future studies will focus on further achieving a higher reaction efficiency as well as carbon atom utilization through the use of more efficient catalysts and solvents.

\section{Conflicts of interest}

There are no conflicts of interest to declare.

\section{Acknowledgements}

This work was supported by the National Science Foundation of China (21673045, 21473037, U1463206, 21433002).

\section{Notes and references}

1 A. Yamaguchi, O. Sato, N. Mimura and M. Shirai, Catal. Commun., 2015, 67, 59-63.

2 Y. Ma, W. Tan, K. Wang, J. Wang, J. Jiang and J. Xu, ACS Sustainable Chem. Eng., 2017, 5, 5880-5886.

3 L. Dehabadi, M. H. Mahaninia, M. Soleimani and L. D. Wilson, ACS Sustainable Chem. Eng., 2017, 5, 29702980.

4 S. Liu, Appl. Energy, 2015, 144, 114-128.

5 L. Yang, X. Yang, E. Tian, V. Vattipalli, W. Fan and H. Lin, J. Catal., 2016, 333, 207-216.

6 Z. Liu, W. Li, C. Pan, P. Chen, H. Lou and X. Zheng, Catal. Commun., 2011, 15, 82-87.

7 K. Zhang, S. Wu, H. Yang, H. Yin and G. Li, RSC Adv., 2016, 6, 77499-77506.

8 B. O. de Beeck, M. Dusselier, J. Geboers, J. Holsbeek, E. Morre, S. Oswald, L. Giebeler and B. F. Sels, Energy Environ. Sci., 2015, 8, 230-240.
9 S. Saravanamurugan and A. Riisager, Catal. Sci. Technol., 2014, 4, 3186-3190.

10 Y. Wang, W. Deng, B. Wang, Q. Zhang, X. Wan, Z. Tang, Y. Wang, C. Zhu, Z. Cao, G. Wang and H. Wan, Nat. Commun., 2013, 4, 2141-2147.

11 D. M. Alonso, S. G. Wettstein and J. A. Dumesic, Green Chem., 2013, 15, 584-595.

12 F. Cao, T. J. Schwartz, D. J. Mcclelland, S. H. Krishna, J. A. Dumesic and G. W. Huber, Energy Environ. Sci., 2015, 8, 1808-1815.

13 T. Wang, M. W. Nolte and B. H. Shanks, Green Chem., 2014, 16, 548-572.

14 H. Chen, J. Tan, Y. Zhu and Y. Li, Catal. Commun., 2016, 73, 46-49.

15 Y. Z. Wang, S. De and N. Yan, Chem. Commun., 2016, 52, 6210-6224.

16 Y. Cui, B. Wang, C. Wen, X. Chen and W. L. Dai, ChemCatChem, 2016, 8, 527-531.

17 C. Wen, Y. Cui, X. Chen, B. Zong and W. L. Dai, Applied Catalysis, B: Environmental, 2015, 162, 483-493.

18 Y. Sun, H. Wang, J. Shen, H. Liu and Z. Liu, Catal. Commun., 2009, 10, 678-681.

19 J. Zheng, H. Lin, X. Zheng, X. Duan and Y. Yuan, Catal. Commun., 2013, 40, 129-133.

20 H. Fan, J. Tan, Y. Zhu, H. Zheng and Y. Li, J. Mol. Catal. A: Chem., 2016, 425, 68-75.

21 D. He, W. Huang, J. Liu and Q. Zhu, Catal. Today, 1999, 51, 127-134.

22 D. H. He, W. G. Huang, J. Y. Liu and Q. M. Zhu, J. Mol. Catal. A: Chem., 1999, 145, 335-338.

23 Y. Sun, H. Wang, J. Shen, H. Liu and Z. Liu, Catal. Commun., 2009, 10, 678-681.

24 B. Wang, Q. Xu, H. Song and G. Xu, J. Energy Chem., 2016, 16, 78-80.

25 A. Y. Yin, C. Wen, W. L. Dai and K. N. Fan, Applied Catalysis, B: Environmental, 2011, 108, 90-99.

26 T. Hayashi, T. Inagaki, N. Itayama and H. Baba, Catal. Today, 2006, 117, 210-213.

27 Y. H. Ke, X. X. Qin, C. L. Liu, R. Z. Yang and W. S. Dong, Catal. Sci. Technol., 2014, 4, 3141-3150.

28 R. K. Purushothaman, J. V. Haveren, D. S. Es, I. MelianCabrera and H. J. Heeres, Green Chem., 2012, 14, 2031-2037.

29 G. Xu, A. Wang, J. Pang, X. Zhao, J. Xu, N. Lei, J. Wang, M. Zheng, J. Yin and T. Zhang, ChemSusChem, 2017, 10, 1390-1394.

30 J. Zhang, X. Liu, M. Sun, X. Ma and Y. Han, ACS Catal., 2012, 2, 1698-1702.

31 F. D. Bobbink, J. Q. Zhng, Y. Pierson, X. Chen and N. Yan, Green Chem., 2015, 17, 1024-1031.

32 J. Y. Zhang, B. L. Hou, A. Q. Wang, Z. L. LI, H. Wang and T. Zhang, AIChE J., 2014, 60, 3804-3813.

33 K. Isobe, M. Kataoka, J. Ogawa, J. Hasegawa and S. Shimizu, New Biotechnol., 2012, 29, 177-182.

34 H. A. Rass, N. Essayem and M. Besson, Green Chem., 2013, 15, 2240-2251.

35 C. P. Ferraz, M. A. Garcia, É. Teixeira-Neto and L. M. Rossi, $R S C$ Adv., 2016, 6, 25279-25285. 
36 N. Mei, B. Liu, J. D. Zheng, K. L. Lv, D. G. Tang and Z. H. Zhang, Catal. Sci. Technol., 2015, 5, 3194-3202.

37 X. L. Tong, Z. H. Liu, L. H. Yu and Y. D. Li, Chem. Commun., 2015, 51, 3674-3677.

38 M. Orazov and M. E. Davis, Proc. Natl. Acad. Sci. U. S. A., 2015, 112, 11777-11782.

39 Y. E. Yan, L. Feng, G. Li, S. Y. Lin, Z. Sun, Y. H. Zhang and Y. Tang, ACS Catal., 2017, 7, 4473-4478.

40 E. Miliordos, S. Caratzoulas and D. G. Vlachos, Appl. Catal., A, 2017, 530, 75-82.
41 N. Ji, T. Zhang, M. Zheng, A. Wang, H. Wang, X. Wang and J. G. Chen, Angew. Chem., Int. Ed., 2008, 47, 8510-8513.

42 Z. Tai, J. Zhang, A. Wang, M. Zheng and T. Zhang, Chem. Commun., 2012, 48, 7052-7054.

43 T. Deng and H. Liu, J. Mol. Catal. A: Chem., 2014, 388, 66-73. 44 T. Ennaert, A. J. Van, J. Dijkmans, C. R. De, W. Schutyser, M. Dusselier, D. Verboekend and B. F. Sels, Chem. Soc. Rev., 2016, 45, 584-611.

45 H. Habe, Y. Shimada, T. Yakushi, H. Hattori, Y. Ano and T. Fukuoka, Appl. Environ. Microbiol., 2009, 75, 7760-7766. 